\title{
PRELIMINARY TREATABILITY TEST OF A NON-CONVENTIONAL INDUSTRIAL WASTEWATER IN THE WOOD SECTOR: COD AND FORMALIN REDUCTION
}

\author{
Fabio Kaczala ${ }^{1}, 2$ \\ Marcia Marques $\stackrel{1}{3}$ \\ William Hogland ${ }^{I}$ \\ ${ }^{1}$ University of Kalmar-HiK, Sweden \\ ${ }^{2}$ The CAPES Foundation, Brazil Ministry of Education, Brazil \\ ${ }^{3}$ Rio de Janeiro State University-UERJ, Rio de Janeiro, Brazil
}

\begin{abstract}
Industrial activities commonly discharge a broad range of synthetic compounds directly into water recipients without previous treatment. Despite the existence of available technologies for industrial wastewater treatment, better understanding of treatment processes is still required, since these waters are relatively complex and usually contain either persistent or recalcitrant compounds. Treatment systems with low costs of implementation, operation and maintenance as well as energy and labor saving processes ought to be developed. Biological treatment systems are potentially good options to meet these requirements. In this study, a preliminary investigation in lab scale was carried out with a Sequencing Batch Reactor -SBR used to treat a non-conventional industrial wastewater generated by a wood-floor industry, located in Nybro, Sweden. The study focused on: (i) formalin reduction in aqueous phase and; (ii) COD reduction. The proposed SBR reached a high efficiency in reducing formalin within the aqueous phase (from $53 \%$ to $98 \%$ ) suggesting the use of formalin by the microorganisms as a primary carbon source. On the other hand, COD reduction $(-34 \%$ to $73 \%)$ was not satisfactory, which is probably related with the presence of polymeric compounds with high molecular weight in the urea-formaldehyde resin. Recommendations for the system improvement are: (i) effluent recirculation; (ii) longer filling periods during each batch and; (iii) both primary and secondary settling/ sedimentation. As a result of very high initial COD contents (ranging between 736-5608 $\mathrm{mg} \mathrm{L}^{-1}$ ), even though a high percentage of reduction is achieved, the final effluent would still not meet the threshold limits for effluent discharges in water bodies. Additional treatment options could be advanced oxidative processes such as ozonation and Fenton.
\end{abstract}

\section{KEYWORDS:}

Sequential Batch Reactor, formaldehyde, Industrial Wastewater, High COD

\section{INTRODUCTION}

Industrial activities generate a large amount of wastewater with a broad range of chemical compounds that impair both the environment and public health. Annually, 300 million tons of 
synthetic compounds are used by different manufacturing processes being discharged afterwards in water bodies without previous treatment [1]. Despite the availability of technologies to treat industrial wastewaters, there is a need for efficient systems with low costs of implementation, maintenance and operation. In terms of economical feasibility, when compared to other technologies, biological systems are in the frontline, being much less costly [2]. Biological treatment has been widely accepted and used for either partial or complete stabilization of biologically degradable substances, present in wastewaters [2]. It is widely reported in literature the use of anaerobic processes in many industries for the treatment of wastewater with relatively high content of organic pollutants due to its performance, cost and energy saving advantages [3, 4, 5, 6]. Industrial wastewaters, particularly those generated after washing/cleaning of machineries and equipment vary both quantitatively and qualitatively in time, which threat the proper function of biological treatment systems. Therefore, there is still a demand for knowledge development regarding operational parameters and how to achieve optimum conditions and improved treatment efficiency $[7,8]$. In the present study, the biological approach for treating a wastewater stream generated in a wood floor industry located at Nybro, Sweden is preliminarily evaluated. The wastewater is generated at the cleaning/washing procedures of machineries that continuously apply ureaformaldehyde resins on the wood particle boards. The main characteristics of such wastewaters are the high contents of formalin and very high content of COD. The objective in this stage of the investigation was to assess the treatability of this wastewater through biological processes and the performance of the treatment system, with focus on: reduction of formalin in aqueous phase and; reduction of COD.

\section{MATERIAL AND METHODS}

The bench-scale experiment was divided in two stages: Stage 1: Microbial growth and attachment onto an inorganic filter media; Stage 2: Treatability experiment.

Due to the intermittent generation of the wastewater to be treated, a Sequencing Batch Reactor (SBR) was proposed (see Figure 1). The system, specifically designed and built up for this experiment consisted of two cylindrical reactors (external diameter $10 \mathrm{~cm}$ and height $21 \mathrm{~cm}$ ) functioning in sequence. The first phase consisted in anaerobic conditions and the second in intermittent aeration to establish alternated aerobic-anoxic conditions (see Table l). The anaerobic phase included the following steps: (i) filling; (ii) anaerobic degradationsedimentation and (iii) discharge. The aerobic-anoxic phase included: (i) filling; (ii) aerationaerobic degradation; (iii) aeration interruption-anoxic phase and; (iv) discharge. 


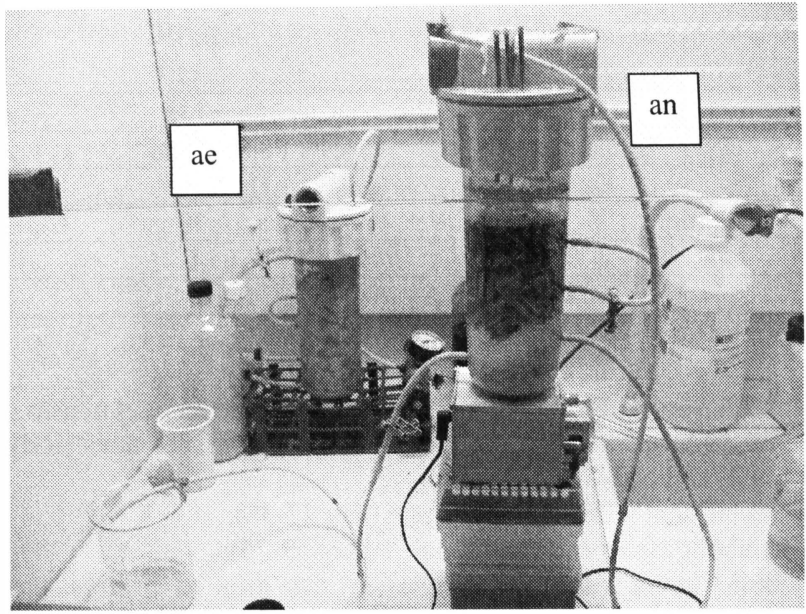

Figure 1: SBR lab-scale constructed for glue wastewater treatment: (an) anaerobic phase; (ae) Intermittent Aeration (aerobic/anoxic phase).

The temperature during the anaerobic and aerobic-anoxic phase ranged between $25-32{ }^{\circ} \mathrm{C}$ (kept through a thermal plate underneath the reactor) and $20-23{ }^{\circ} \mathrm{C}$ respectively (room temperature). Whereas the filling procedure was done with a peristaltic pump (Watson Marlow-Alitea M20 10-100 rpm Dual channel) in an up-flow mode, the discharge was done in a down-flow by gravity. Before filling the anaerobic phase, the influent had the $\mathrm{pH}$ adjusted to the range between $\mathrm{pH}$ 6-7 either with a $\mathrm{NaOH}(1 \mathrm{M})$ or $\mathrm{HCl}(0.1 \mathrm{M})$, except for those batches where the intention was to investigate the influence of the $\mathrm{pH}$ over the system efficiency.

Stage 1 - Microbial growth and attachment phase: Activated sludge taken from the Kalmar Municipal Wastewater Treatment Plant (KWWTP) was used as inoculum to promote microbial growth and attachment onto the filter carriers. The sludge was stored at $4{ }^{\circ} \mathrm{C}$. In order to put the microorganisms in contact with the carriers, $600 \mathrm{ml}$ beackers were filled with $100 \mathrm{ml}$ (4.\&6 g MLVSS/L) of activated sludge plus synthetic medium (see Table 2) and the filter carriers (ceramic and polymers). The beackers were immersed in a water bath, kept at constant temperature of $30{ }^{\circ} \mathrm{C}$. During a one-month period, every second day the activated sludge within the beackers was carefully disposed off and replaced with a fresh batch prepared with the same material previously mentioned (activated sludge + synthetic medium). The procedure was handled carefully in order to avoid biofilm slough off. After 30 days, filter carriers were put into the cylindrical reactors and the treatability experiment had commenced. 
Table 1. Physical and hydraulic characteristics of the SBR phases.

\begin{tabular}{|c|c|c|c|}
\hline Phases & Anaerobic & Aerobic & Anoxic \\
\hline Process & Fluidized bed & Packed bed & Packed bed \\
\hline Flow & Up flow & Up flow & Up flow \\
\hline Filter carriers & Polymeric $(50-70 \mu \mathrm{m}$ pore size $)$ & Ceramic rings* & Ceramic rings* \\
\hline Total vol & $1.65 \mathrm{~L}$ & $1.65 \mathrm{~L}$ & $1.65 \mathrm{~L}$ \\
\hline Effective vol. & $0.6 \mathrm{~L}$ & $0.6 \mathrm{~L}$ & $0.6 \mathrm{~L}$ \\
\hline
\end{tabular}

* Porosity non-defined.

Stage 2 - Effluent Treatment Evaluation: This stage was divided in 4 phases consisting in:

(i) feeding with an influent initially diluted 20 times + co-substrates $\left(\mathrm{KH}_{2} \mathrm{PO}_{4}, \mathrm{~K}_{2} \mathrm{HPO}_{4}\right.$, Glicose, $\mathrm{CuCl}_{2}$ and $\mathrm{NH}_{4} \mathrm{Cl}$ ) (day 1-26);

(ii) feeding with influent without co-substrate (day 27-38);

(iii) induced metabolic stress and starvation (day 39-75);

(iv) Post-metabolic stress (day 76-120) when the dilution factors used during the experiment were progressively reduced until it reached the condition of effluent with no dilution by the $100^{\text {th }}$ day.

In every cycle, influent and effluents from the following four sampling points were analyzed: anaerobic influent (S1); anaerobic effluent (S2); aerobic effluent (S3) and anoxic effluent (S4). The following parameters and analytical methods were used: pH (Digital pH meter WTW Multi 340i), Dissolved Oxygen (Digital Oxymeter WTW Multi 340i), Formalin and COD (LCK 325 and LCK 114 respectively according Dr Lange Düsseldorf, Germany). Moreover, $\mathrm{CO}_{2}$ and $\mathrm{CH}_{4}$ were monitored (8 samples) with Buch \& Holm GA 2000 gas analyzer. A summary of the operational conditions is found in Table 3.

Table 2. Synthetic medium used for the microbial attached growth.

\begin{tabular}{|c|c|c|}
\hline & & mg $100 \mathrm{~mL}^{-1}$ \\
\hline \multirow{5}{*}{ 冚 } & $\mathrm{NH}_{4} \mathrm{Cl}$ & 160 \\
\hline & $\mathrm{CaCl}_{2} * 2 \mathrm{H}_{2} \mathrm{O}$ & 22.5 \\
\hline & $\mathrm{MgCl}_{2} * 6 \mathrm{H}_{2} \mathrm{O}$ & 30 \\
\hline & $\mathrm{FeCl}_{3} * 4 \mathrm{H}_{2} \mathrm{O}$ & 6 \\
\hline & $\mathrm{C}_{6} \mathrm{H}_{12} \mathrm{O}_{6}$ & 2000 \\
\hline \multirow{2}{*}{$\begin{array}{c}\text { Buffer } \\
\text { Solution }\end{array}$} & $\mathrm{KH}_{2} \mathrm{PO}_{4}$ & 81 \\
\hline & $\mathrm{K}_{2} \mathrm{HPO}_{4}$ & 113 \\
\hline \multirow{8}{*}{ 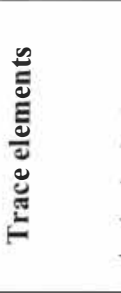 } & $\mathrm{MnCl}_{2} * 4 \mathrm{H}_{2} \mathrm{O}$ & 0.85 \\
\hline & $\mathrm{H}_{3} \mathrm{BO}_{3}$ & $0.0 \notin 5$ \\
\hline & $\mathrm{ZnCl}_{2}$ & $0.0 \notin 5$ \\
\hline & $\mathrm{CuCl}_{2}$ & 0.009 \\
\hline & $\mathrm{Na}_{2} \mathrm{MoO}_{4} * 2 \mathrm{H}_{2} \mathrm{O}$ & 0.003 \\
\hline & $\mathrm{CoCl}^{*} 6 \mathrm{H}_{2} \mathrm{O}$ & 0.85 \\
\hline & $\mathrm{NiCl}_{2} * 6 \mathrm{H}_{2} \mathrm{O}$ & $0.0 \notin 5$ \\
\hline & $\mathrm{Na}_{2} \mathrm{SeO}_{3}$ & $0.0 \notin 5$ \\
\hline
\end{tabular}


Kalmar ECO-TECH '07

KALMAR, SWEDEN, November 26-28, 2007

Table 3. Summary of the operational conditions of the SBR.

\begin{tabular}{|c|c|c|c|c|c|c|c|c|c|c|c|c|}
\hline \multirow{2}{*}{$\begin{array}{c}\text { Process } \\
\text { Stagc }\end{array}$} & \multicolumn{4}{|c|}{ Anaerobic } & \multicolumn{4}{|c|}{ Aerobic } & \multicolumn{4}{|c|}{ Anoxic } \\
\hline & $0-26$ & $26-38$ & $*$ & $76-120$ & $0-26$ & $26-38$ & $*$ & $76-120$ & $0-26$ & $26-38$ & $*$ & $76-120$ \\
\hline $\begin{array}{l}\text { HRT } \\
\text { (days) }\end{array}$ & $2-5.5$ & $2-5$ & & 3 & $1-1.5$ & $1-2$ & & 2 & $0.5-2$ & $1-3$ & & 1 \\
\hline $\begin{array}{l}\text { Filling } \\
(\mathrm{min})\end{array}$ & 30 & 30 & & $60-90$ & 30 & 30 & & 30 & - & - & $n$ & - \\
\hline $\begin{array}{l}\text { Degrad } \\
\text { (days) }\end{array}$ & $\sim 2-5.5$ & $\sim 2-5$ & 空 & $\sim 3-5$ & $\sim 1-1.5$ & $\sim 1-2$ & $\stackrel{0}{0}$ & $\sim 2-3$ & $\begin{array}{c}\sim 0.5- \\
2\end{array}$ & $\sim 1-3$ & $\stackrel{0}{5}$ & $\sim 1-2$ \\
\hline $\begin{array}{l}\text { Temp } \\
\left({ }^{\circ} \mathrm{C}\right)\end{array}$ & $29-32$ & $29-32$ & & $25-32$ & $20-23$ & $20-23$ & & $20-23$ & $20-23$ & $20-23$ & & $20-23$ \\
\hline $\mathrm{pH}$ & $3.5-10$ & $6-10$ & & $4.5-10$ & $3.3-6$ & $6-9$ & & $6-9$ & $3.5-6$ & $7-9.2$ & & $8.4-9$ \\
\hline
\end{tabular}

*The induced metabolic stress with increased Hydraulic Retention Times-HRT.

\section{RESULTS}

COD reduction: The total COD reduction along 26 cycles during four months (average of 6.5 cycles per month) ranged between $-34 \%$ and $73 \%$ (Figure 2 ). The observed oscillation in efficiency can be related to the presence of polymeric compounds in the glue, with a relatively high molecular weight characterized by persistence and in the worst case, recalcitrance [9] and changes in the running conditions, such as nutrients availability. As a consequence, whereas in some cycles $(5,6,9,11,22$ and 23$)$ the system achieved a satisfactory efficiency, in others, it didn't. During Cycle 3, for instance, the insignificant reduction of total COD $(3 \%)$ was probably due to the previous metabolic stress suffered by the system, with higher retention times than usual and a consequent starvation process. According to [10] the lack of nutrients within a SBR resulted in inhibition of microbial metabolism with a low rate of biological transformation and mineralization of organic compounds. Moreover, during Cycle 19 , the total COD reduction was negative $(-34 \%)$, suggesting either the production of particularly persistent or recalcitrant by-products as a result of biological transformation of the original compounds in the influent, a phenomenon already described in the literature [11]. According to [11], the majority of the organic compounds in an effluent after biological treatment was not detected in the original influent, but were actually produced by the system. Yet, according to the authors, the environmental conditions $(\mathrm{pH}$, nutrient deficiency, presence of toxic compounds) and operational parameters play important roles as regards certain byproduct compounds and its building up processes [11]. Similarly, [6] reported negative reduction of COD in a UASB system until the $40^{\text {th }}$ week of operation, correlating it with difficult hydrolysis and consequent accumulation of dissolved organic matter.

Nevertheless, in the present investigation, the negative reduction of COD (partial and total) in some cycles remains with no explanation. [11] mention the presence of dissolved organic matter such as exopolymeric substances produced by attached biomass that possibly contribute to the organic matter content. Advanced analytical methods are required to detect these substances, being this investigation planned for a near future. 


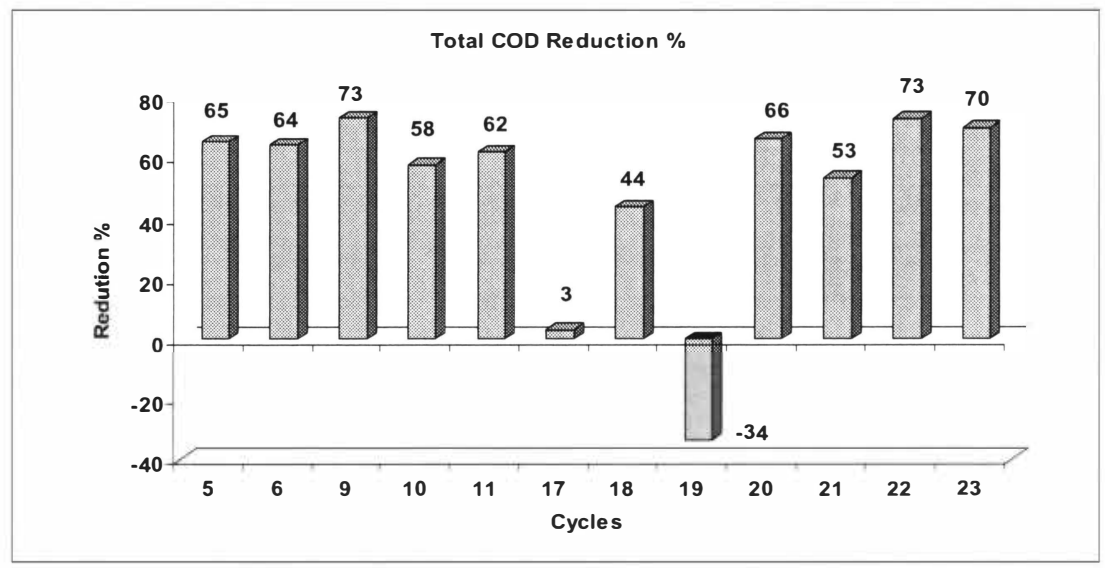

Figure 2: Total COD reduction achieved by the SRB including all phases.

In order to identify the treatment phase responsible for the COD increase, Figure 3 shows the reduction in each phase of the biological process (anaerobic-aerobic-anoxic). During Cycles 6 and 19, the anaerobic phase was responsible for a COD increase. It can also be observed during the anoxic phase; low negative reductions in Cycles 11, 17, 18, 20 and 21 (see Figure $3)$.

Non satisfactory values of COD reduction at the anaerobic phase may be related to the presence of easily degradable organics as carbon sources for the microbiological metabolism, which in turn, might inhibit the production of specific enzymes capable of transforming and degrading more complex compounds. Still based on Figure 3 the percentage of COD reduction showed a reducing trend along the experiment. This fact can result from the decrease of dilution factor with consequent raise of persistent and recalcitrant compounds.

Formalin Reduction: In Figure 4 a total formalin reduction ranging between 53 and $98 \%$ along the experiment is observed. While the formaldehyde toxicity has been widely reported in literature, in the present study it was considered irrelevant. The results suggested that formaldehyde was actually used as a primary carbon source by the attached biomass, principally when considering both anaerobic and aerobic phases (Figure 5). In a previous study with the same source of wastewater, [12] mention the possibility of antagonistic effects with reduced formaldehyde toxicity when in the presence of other compounds. Such hypothesis requires further investigation. 


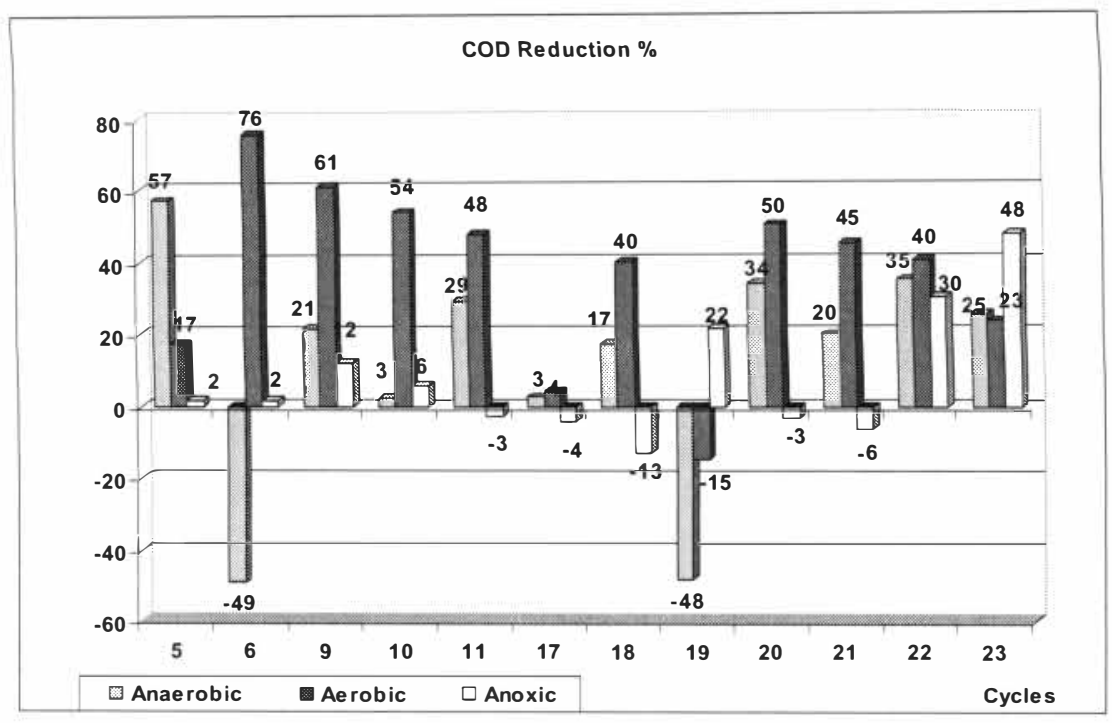

Figure 3: COD reduction efficiency of the different biological phases in the SBR.

An interesting fact was observed during the cycle 19, when the system performed its lowest efficiency regarding formaldehyde reduction $(53 \%)$ and COD $(-34 \%)$. This cycle coincided with the lowest values of formaldehyde and COD in the influent $\left(24 \mathrm{mg} \mathrm{L}^{-1}\right.$ and $737 \mathrm{mg} \mathrm{L}^{-1}$ respectively).

Regardless the $\mathrm{pH}$ variation at the anaerobic influent, the system presented a buffering capacity in the range of $6<\mathrm{pH}<7$, principally taking into account the cycles 9-13 and 17-24 (Figure 6). The outlet $\mathrm{pH}$ in the acidic range suggests the presence of organic acids, and a formaldehyde shock loading (221 mg HCOH L $\mathrm{mgy}^{-1}$ ) at cycle 25 might be the principal cause of an outlet $\mathrm{pH}$ of 3.9. [13], highlight that a typical response of organic shock loading is that $\mathrm{pH}$ decreases down to an acidic range as a consequence of organic acids accumulation,

Figures 7 and 8 show the $\mathrm{pH}$ variation within the intermittently aerated reactor. It is clearly observed that whereas the $\mathrm{pH}$ is raised during the aerobic phase, when the aeration is turned off a decreasing trend for the $\mathrm{pH}$ occurs. No significant variation of inlet and outlet $\mathrm{pH}$ is observed, being reasonable to associate that with a buffering capacity of the system as a whole, both for the neutral (anaerobic phase) and alkaline range. Further investigation of the nitrification-denitrification process is expected to bring better understanding as regards $\mathrm{pH}$ dynamics along the treatment system, principally within the intermittently aerated phase. Similarly to the anaerobic reactor, a pH decrease after cycle 25 suggests the system was negatively affected by formaldehyde shock loading as already mentioned before. 
Kalmar ECO-TECH '07

KALMAR, SWEDEN, November 26-28, 2007

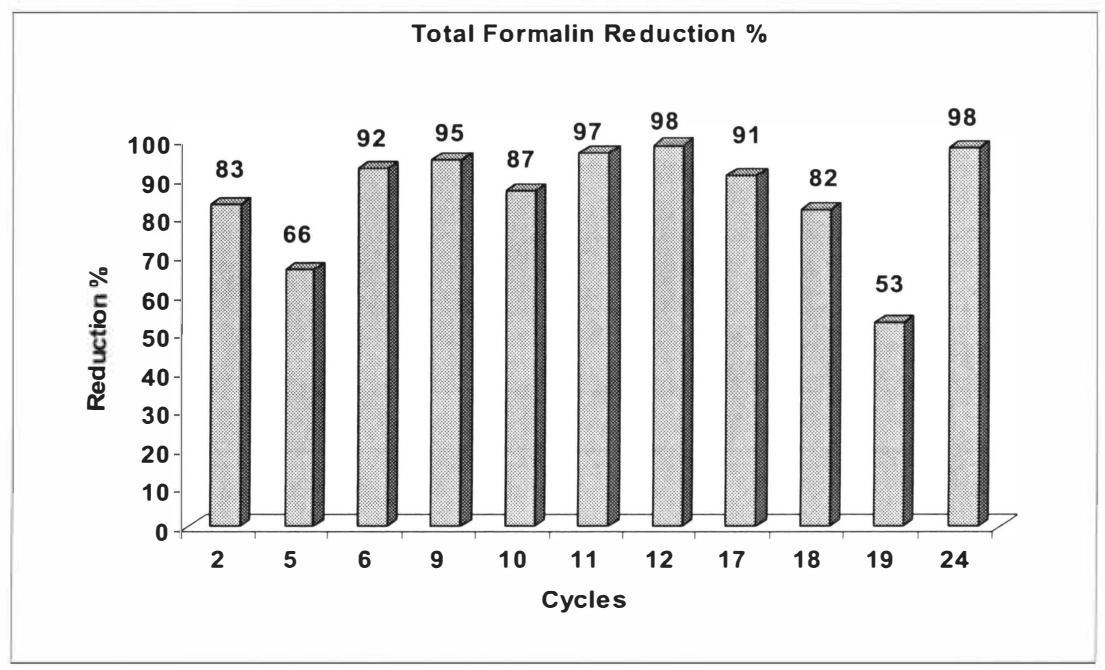

Figure 4: Total formalin reduction achieved by SRB including all phases.

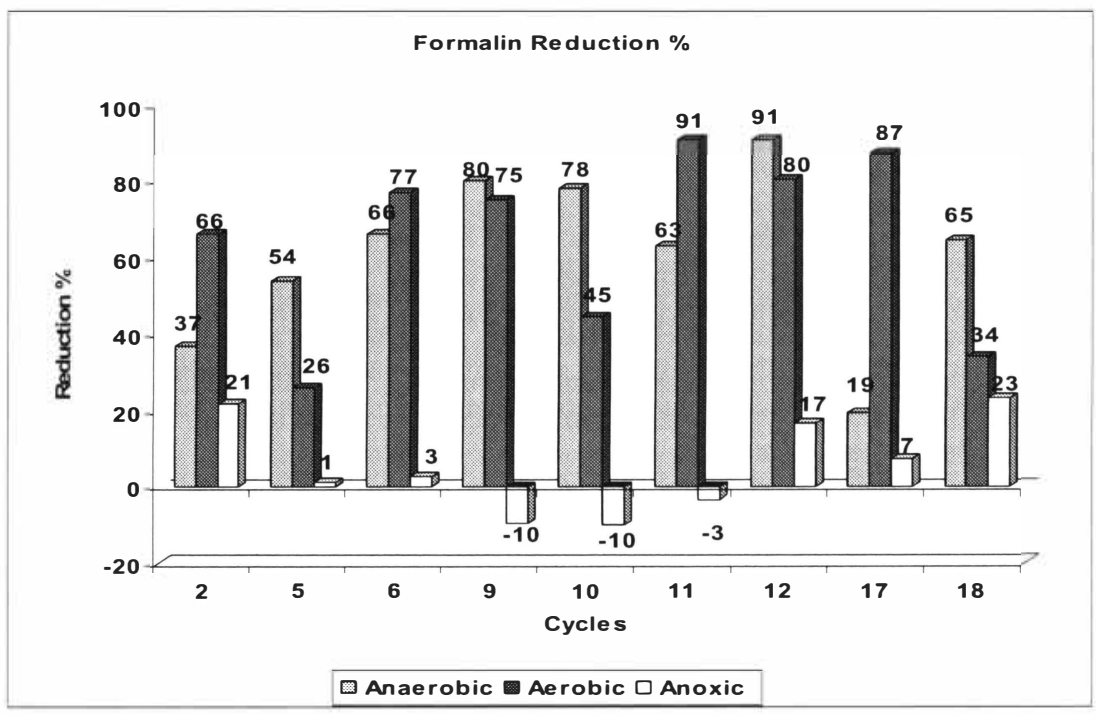

Figure 5: Formalin reduction efficiency on different biological phases of the SBR. 


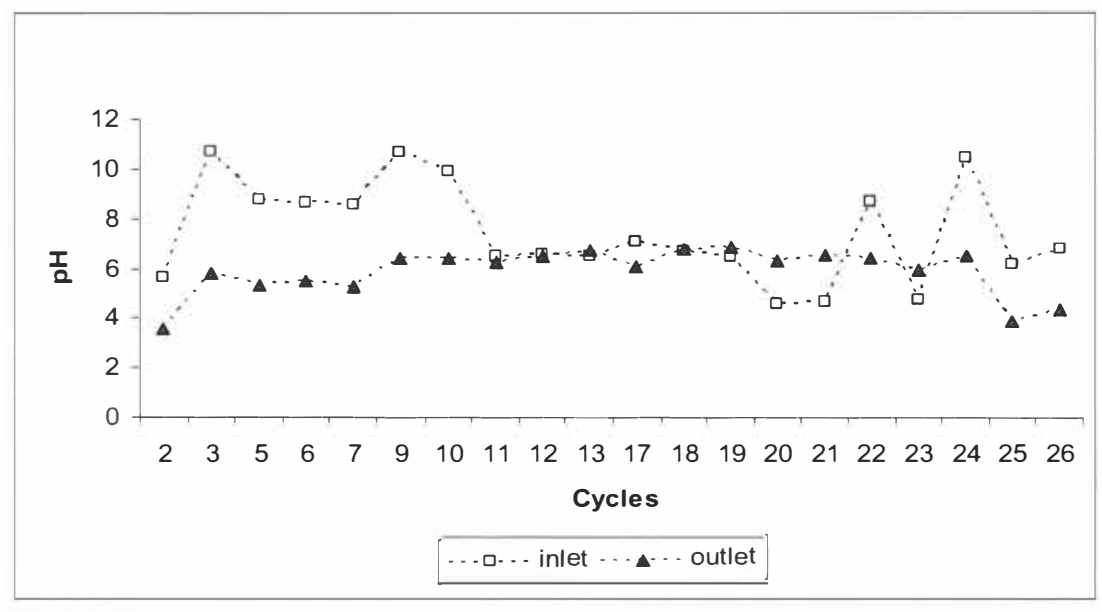

Figure 6: Inlet and Outlet values of $\mathrm{pH}$ within the anaerobic phase along the experiment

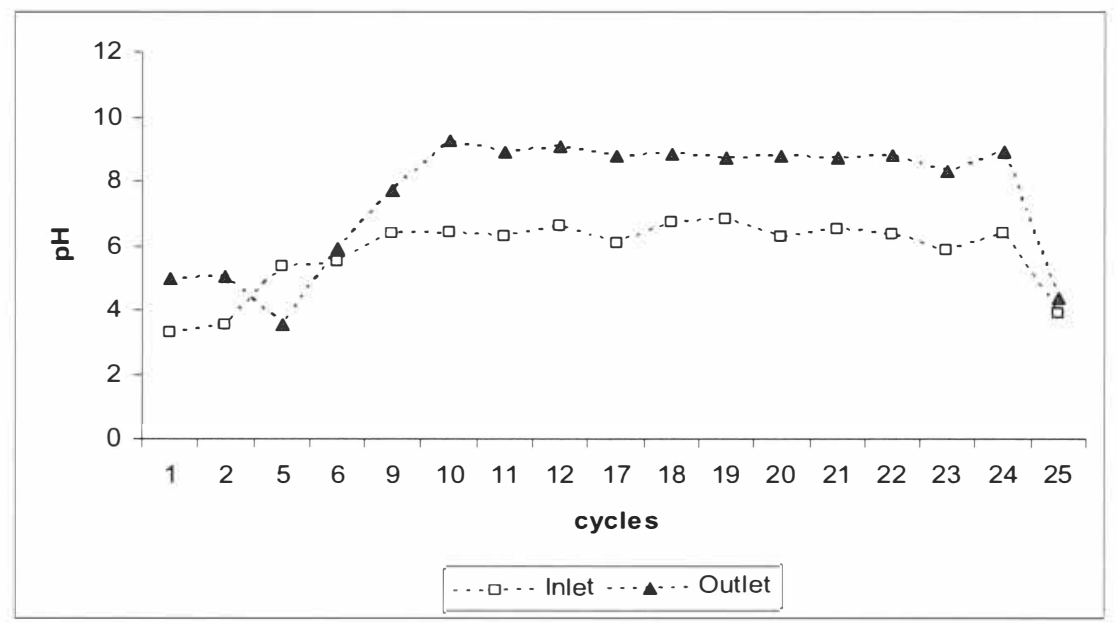

Figure 7: Inlet and Outlet values of $\mathrm{pH}$ within the aerobic phase along the experiment 


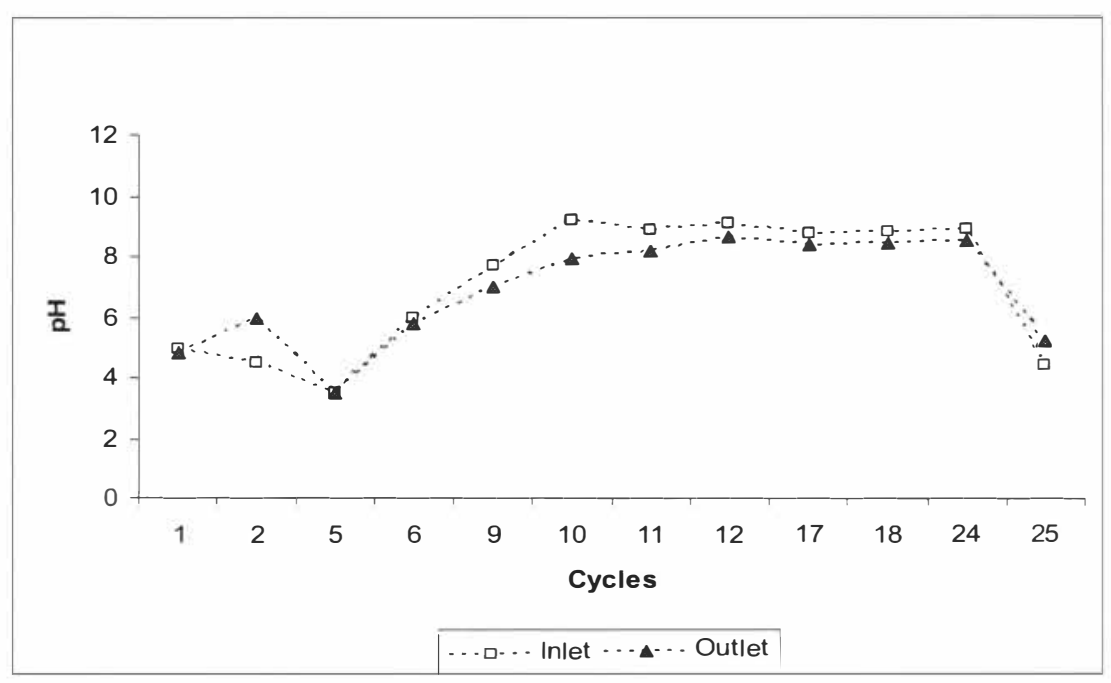

Figure 8: Inlet and Outlet values of $\mathrm{pH}$ within the anoxic phase along the experiment

\section{CONCLUSIONS}

According to the results, the proposed system in a bench scale showed capacity to remove with high efficiency formaldehyde ( $53 \%$ to $98 \%$ ), suggesting the utilization of formaldehyde as a carbon source by microorganisms. On the other hand, the system did not achieve a satisfactory COD reduction $(-34 \%$ to $73 \%)$, which might be related to the presence of either persistent or recalcitrant polymeric compounds with high molecular weight at the Ureaformaldehyde resins. Recommendations for further investigation are: (i) effleent recirculation; (ii) longer feeding periods; (iii) primary and secondary settling/sedimentation systems.

It is important to emphasize that even though the treatment system might be able to achieve high efficiency in reducing COD, very high initial COD values would still result in effluents with values above the threshold limits for effluent discharge. Options for a final polishing include advanced oxidation processes such as ozonation and Fenton.

\section{AKNOWLEDGEMENTS}

The CAPES Foundation - Brazil Ministry of Education is acknowledged for the first author's PhD scholarship. The authors are thankful to the financial support from AB Gustaf Kähr and particularly the relevant assistance from the Environmental Manager Mr Ake Erlandsson. The financial support from Akzo Nobel, Beckers Acroma, Swedwood International and Kalmar Energi and Swedish Institute is here recognized. 


\section{REFERENCES}

1. Schwarzenbach, R. P., Escher, B.I., Fenner, K., Hofstetter, T.B., Johnson, C.A., Von Gunten, U. \& Wehrli, B. 2006. The Challenge of Micropollutants in Aquatic Systems. Science. 313 : 1072-1077.

2. Cheremisinoff, P.N. 1994. Biomanagement of Wastewater and Wastes. $221 \mathrm{pp}$. Water and Wastewater Treatment Guidebooks. Prentice Hall Ed, New Jersey, USA.

3. Chinnaraje S. \& Venkoba Rao, G. 2006. Implementation of an UASB anaerobic digester at bagasse-based pulp and paper industry. Biomass and Bioenergy. 30:273-277

4. Mahmoud, N. 2002. Anaerobic Pre-treatment of sewage under low temperature (158C) conditions in an Integrated UASB-Digester System. PhD Thesis, Wageningen University, Wageningen, The Netherlands.

5. Oktem, Y.A., Ince, O., Donnely, T., Sallis, P., \& Ince, B.K. 2006. Determination of optimum operating conditions of an acidification reactor treating a chemical synthesis-based pharmaceutical wastewater. Process Biochemistry. 41:2258e2263

6. Luostarinen, S., Sanders, W., Kujawa-Roeleveld, K. \& Zeeman, G. 2007. Effect of temperature on anaerobic treatment of black water in UASB-septic tank systems. Bioresource Technology. 98: 980 - 986

7. Leitão, R.C, santaella, S.T., Van handeel, A.C., Zeeman, G. \& LETTINGA, G. 2006. The effects of hydraulic and organic shock loads on the robustness of upflow anaerobic sludge blanket reactors treating sewage. Water Science and Technology. 54:49-55.

8. Mc Kinney, R.E. 2004. Environmental Pollution Control Microbiology. Ed Michael D. Meyer. Dept. of Civil and Environmental Engineering, Georgia Institute of Technology. Atlanta, Georgia, USA.

9. Garrido, J.M., Méndez, R. \& Lema, J.M. 2000. Treatment of wastewaters from a formaldehyde-urea adhesives factory. Water Science and Technology. 42:293-300

10. Wang, Z.W., Li, Y., Zhou, Jia-Qi \& Liu, Y. 2006. The influence of short-term starvation on aerobic granules. Process Biochemistry. 41:2373-2378

11. Aquino, S.F. \& Stuckey, D.C. 2006. Chromatographic characterization of dissolved organics in effluents from two anaerobic reactors treating synthetic wastewater. Water Science and Technology. 54: $193-198$

12. Kaczala, F., Marques, M. \& Hogland, W. 2007. The study of formaldehyde Toxicity over Activated Sludge (In Portuguese). In: 248 Congresso Brasileiro de Engenharia Sanitária e Ambiental. 2-7 September, 2007. Belo Horizonte, Minas Gerais - Brazil

13. Leitão, R.C., Van Handeel, A.C., Zeeman, G. \& Lettinga, G. 2006. The effects of operational and environmental variations on anaerobic wastewater treatment systems: A review. BioresourceTechnology.97:1105-111 